\title{
DIFFERENTIAL INHIBITION OF THE BRAIN ACETYLCHOLINESTERASE MOLECULAR FORMS FOLLOWING SARIN, SOMAN AND VX INTOXICATION IN LABORATORY RATS
}

\author{
Jiři Bajgar \\ Military Medical Academy Hradec Králové; (Rector: doc. MUDr. S. Býma, CSc.)
}

\begin{abstract}
Summary: The female Wistar rats were intoxicated (i.m.) with sarin, soman and VX in doses equal to $1_{x_{L D D}}$ and pontomedullar areas of the brain were prepared, homogenized, centrifuged and in these samples, acetylcholinesterase (AChE, EC 3.1.1.7) activities were determined. In the same samples, AChE was separated using polyacrylamide gel electrophoresis and AChE molecular forms were detected and densitometrically evaluated. In control animals, AChE was separated into four forms differing in their electrophoretic mobility and their quantitative content in the sample. The form with lowest electrophoretic mobility represent the main part of AChE activity constituting the whole enzymatic activity. Following intoxication with the nerve agents mentioned, the whole AChE activity in the pontomedullar area of the brain was decreasing in intervals of ten minutes (soman and sarin) or one hour (VX). The AChE activity at the time of death (or terminal stage) was represented 5-30 \% of controls. Molecular forms of AChE were inhibited in different extent: the form with lowest electrophoretic mobility was diminished to zero level while the form with the highest mobility was practically unaffected, independently on the type of nerve agent. From quantitative expression of percentage content of the forms vs their activity we can imply that values of the total AChE activity represent the „mean“ activity of the forms determined.
\end{abstract}

Key words: Acetylcholinesterase; Molecular forms; Brain; Rat; Sarin; Soman; VX

\section{Introduction}

The threat of the use of chemical weapons not only in military conflicts but also in terroristic attacks is not excluded at present as it was clearly demonstrated in Tokyo (27) and Matsumoto (44) cities (sarin attack in the subway). The very actual group of these chemicals are organophosphates (OP) including nerve agents. The most important nerve agents are represented by sarin (O-isopropyl methylphosphonofluoridate), soman (O-pinacolyl methylphosphonofluoridate) (these two compounds belong to so called Gcompounds) and VX (O-ethyl S-2-diisopropylaminoethyl methyl phosphonothiolate) (V-compounds). Moreover, there are produced many organophosphorus compounds in the civilian facilities and used in industry, agriculture, medicine etc. Basic mechanism of action and antidotal treatment for these compounds are in principle the same and therefore some conclusions from this paper can be applied in the civilian medicine.

From the point of pharmacodynamics and therapeutic possibilities, soman represents the most serious poison: its toxicity is comparable with that of sarin and VX $(7,8,15,16,35)$ but therapeutic efficacy of antidotal treatment with present and perspective drugs is not good enough $(14,17,23,24,29)$. This is probably a reason for in- tensive research dealing with soman intoxication and its treatment.

Soman and sarin are quickly resorbed at all routes of administration including inhalation, percutaneous and oral administration (7) and inhibit cholinesterases (preferably acetylcholinesterase, AChE, EC 3.1.1.7) in the central and peripheral nervous system. Because of high lipophility of soman, it posses high affinity to brain $\operatorname{AChE}(1,8)$. Sarin is less lipophilic, however, its affinity to the brain AChE is also very high (8).

Soman and sarin are detoxified in the liver, plasma $(21,37)$, according to some authors also in the lung (34) and therefore this part is excluded from the toxic effect. The losses of G-compounds in the organism are caused also by binding to nonspecific esterases and this part of soman and sarin is not able to cause toxic effect. It was assessed that only $1-3 \%$ from the dose administered of the both compounds inhibited $\mathrm{AChE}$ in the brain, i.e. 1-3\% of the dose administered caused the basic toxic effect $(7,22,26,34)$. Another factor (up to now not very elucidated) influencing soman and sarin poisoning is an existence of a depot in the organism from which the nerve agent can be released and causes new attack of intoxication. This depot was described for the skin, erythrocytes, muscles and lung $(8,22)$. Bearing in mind very low portion of the dose administered causing 
basic toxic effect (1-3\%), it is clear that releasing of a very small quantity of sarin and soman can influence significantly survival or death of intoxicated organism independently on the treatment.

On the other hand, $\mathrm{V}$ compounds are not detoxified in the organism (7). Probably this is a reason of higher toxicity of $\mathrm{V}$ compounds in comparison with G-compounds. The effect of V-compounds (especially VX) is prolonged in comparison with sarin and soman (42). The mechanism of action of VX is inhibition of AChE preferably in peripheral nervous system $(8,28)$. However, the inhibition of $\mathrm{AChE}$ in the brain parts was described to be selective and the most marked in the pontomedullar area of the brain $(7,8)$.

The evidence supporting AChE as the primary site of the both OP and nerve agents action has been summarized by many authors $(6,19,28,39)$. It includes the following observations: symptoms of OP poisoning are similar to those of the AChE inhibitor physostigmine; the in vivo LD50 for a variety of OP correlates well with the inhibition efficacy to $\mathrm{AChE}$ determined in vitro; and $\mathrm{ChE}$ reactivators (e.g. oximes), anticholinergics (e.g. atropine) and spontaneously reactivating $\mathrm{AChE}$ inhibitors (e.g. carbamates) can reduce OP toxicity. However, despite the model's pragmatic success, a variety of data are inharmonious with AChE inhibition as the only important biochemical event in OP intoxication.

Thus, basic mechanism of action of nerve agents - similarly as for other OPs - is an intervention into cholinergic nerve transmission via irreversible inhibition of $\mathrm{AChE}$ and other hydrolases $(6,28,39)$. Monitoring of cholinesterase changes - their development during the intoxication is at present the best reflection of a severity of OP poisoning as well as a reaction to antidotal therapy.

Both enzymes (AChE and butyrylcholinesterase, BuChE, EC 3.1.1.8) exist in multiple molecular forms (2$5,12,25,30,36,38)$. The activities of these forms are also influenced by many factors. The function of these forms is not known at present, however, their presence in the membrane structures at physiological conditions was demonstrated (5). There are a few data describing the changes of AChE molecular forms following intoxication with highly toxic OPs (25). Some experiments were performed with relatively less toxic OP $(4,10,30)$.

Molecular forms of $\mathrm{AChE}$ showed different sensitivity to inhibitors in vitro $(4,7,31)$ and in vivo $(11,13,30,40,41)$. Following DFP (40) and highly toxic OPs (our results, and 25 ), the form with high molecular weight was the most sensitive. Intoxication with Parathion and Neguvon (less toxic OPs) caused medium inhibition of some forms of $\mathrm{AChE}$ $(7,13,43)$. One can suppose that following determination of the whole AChE activity, a „mean“ of activities of the forms could be determined: in case of death, some forms of $\mathrm{AChE}$ reached an unmeasurable level, some of them were unchanged: the whole AChE activity was about $10 \%$ of controls. Thus, determination of AChE molecular forms can contri- bute to more precise diagnosis of OP intoxication.

This approach could improve the therapy of OP and soman poisoning and simultaneously it could contribute to better understanding of cholinergic nerve transmission and thus to better insight to pharmacology and neuropharmacology in general.

Comparison of changes of AChE activity and its molecular forms following soman, sarin and VX poisoning is the aim of this study.

\section{Material and methods}

\section{Enzyme source}

Female Wistar rats (Velaz, Praha) weighing 170-200 g were used. The animals were killed by bleeding from the carotid artery, the brains were immediately removed, washed with saline and frozen. Then they were thawed and homogenized in an Ultra Turrax homogenizer (Janke and Kunkel, Germany) in distilled water and $0.5 \%$ Triton X-100 to make a $10 \%(\mathrm{w} / \mathrm{v})$ homogenate. The homogenate was centrifuged for $60 \mathrm{~min}$ at $105.000 \mathrm{~g}$ and $4^{\circ} \mathrm{C}$ (MSE, 50 T.C., England) and the supernatant was used as a source of soluble AChE.

\section{Disc electrophoresis}

Electrophoresis of the samples $(20 \mu \mathrm{l})$ in $7,5 \%$ polyacrylamide gels was carried out for $60 \mathrm{~min}$ at $240 \mathrm{~V}$ and 40 $\mathrm{mA}$ as it was described previously (5).

\section{Determination of AChE activity}

$\mathrm{AChE}$ activity in the gel was demonstrated with acetylthiocholine iodide (Lachema Brno, Czech Republic) as substrate by the method described earlier $(4,5)$. Colorimetric assay for AChE activity in the samples without electrophoretic separation was carried out according to Ellman et al. (18), with acetylthiocholine iodide as substrate and 5, 5dithiobis-2-nitrobenzoic acid (Serva, Heidelberg, Germany) as chromogen. AChE activity was expressed as $\mu \mathrm{mol}$ of substrate hydrolysed per min per g wet wt. tissue or as percent of controls.

\section{Densitometric evaluation}

Following staining the gels were scanned on a Vitatron densitometer (Sci. Instr. Eefde, Holland) and the activity was expressed in arbitrary units or as percent of controls.

\section{Inhibition of AChE and its molecular forms by OPs in vivo}

Female rats (Velaz) weighing 180-200 g were divided into groups $(n=6)$. The animals in control group obtained saline, the animals in experimental groups were injected with sarin, soman and VX compound in a dose approximately $1 \mathrm{x} \mathrm{LD}_{50}$ (sarin - $0.2 \mathrm{mg} / \mathrm{kg}$, soman - $0.12 \mathrm{mg} / \mathrm{kg}$ and $\mathrm{VX}-0.05 \mathrm{mg} / \mathrm{kg}$ ). The animals in both control and experimental groups were killed at different time intervals and supernatants from the pontomedullar area of the brain were prepared as described. The whole AChE activity in samples 
removed 1, 3,5 and $10 \mathrm{~min}$ (sarin, soman) and 1,5,15,30 and $60 \mathrm{~min}(\mathrm{VX})$ after intoxication was determined. Samples removed 5 and $10 \mathrm{~min}$ (sarin, soman) and 30 and $60 \mathrm{~min}(\mathrm{VX})$ after intoxication were used for electrophoretic separation. The first interval chosen represents developed intoxication, the second one is practically the time of death.

The handling of experimental animls was under the supervision of the Ethics Committee of the Medical Faculty, Charles University, Hradec Králové.

\section{Statistical evaluation}

The results were calculated as the means with their 95\% confidence limits. The differences between groups were evaluated by analysis of variance. Homogeneity of experimental groups was tested by Bartlett 's test. All calculations were done on a Hewlett Packard 9830.

\section{Results}

Normal AChE activity and its molecular forms

AChE activity in the brain homogenate was found to be $6 \mu \mathrm{mol}$ of substrate hydrolysed per min per $\mathrm{g}$ wet wt. of tissue. AChE activity in the supernatant - i.e. activity of the soluble AChE - was approximately $95 \%$ of the activity in the homogenate.

Following electrophoretic separation of soluble rat brain AChE, the presence of four AChE molecular forms was demonstrated. They were designated by arabic numerals 14. Their percentage distribution was as follows: the forms with the highest electrophoretic mobility (forms 1,2) comprised about $1 / 5$ of the whole activity and the forms with the lowest mobility (forms 3,4) contained the remaining ones, i.e. these forms represent the main part (about $80 \%$ ) of the whole AChE activity (Table 1).

Table 1: Percentual distribution of the AChE forms according to densitometric evaluation

\begin{tabular}{|c|c|c|c|c|}
\hline form & 1 & 2 & 3 & 4 \\
\hline$\%$ & $8.0 \pm 2.4$ & $10.1 \pm 2.8$ & $33.9 \pm 3.5$ & $48.0 \pm 3.1$ \\
\hline
\end{tabular}

\section{Inhibition of the total AChE activity}

The course of intoxication as well as a decrease (i.e. inhibition) of AChE activity was very fast for sarin and soman - within ten minutes the brain AChE activity reached the zero level (Fig. 1). On the other hand, following intoxication with VX, the time course of AChE inhibition was prolonged and reached to unmeasurable activity within one hour (Fig. 2). It was possible to calculate the half-lives of AChE inhibition using semilogarithmic transformation where the dependence of AChE activity changes vs. time gives the straight lines (Fig. 3).The half-life values were as follows: $24.1 \pm 3.8$ (VX), $3.1 \pm 0.56$ (sarin) and $2.2 \pm 0.48 \mathrm{~min}$ (soman), respectively.
Fig. 1: Changes of $\mathrm{AChE}$ activities following intoxication with soman (S1) and sarin (S2). The results are means only, for errors see Table 2.

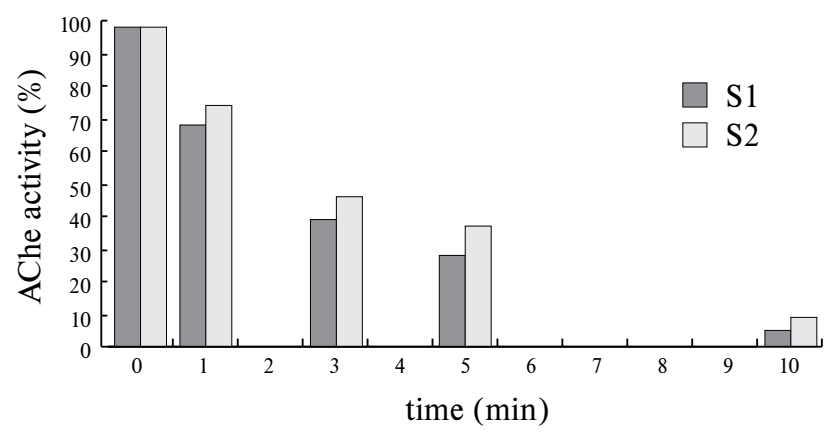

Fig. 2: Changes of $\mathrm{AChE}$ activities following intoxication with VX (S1). The results are means only, for errors see Table 2.

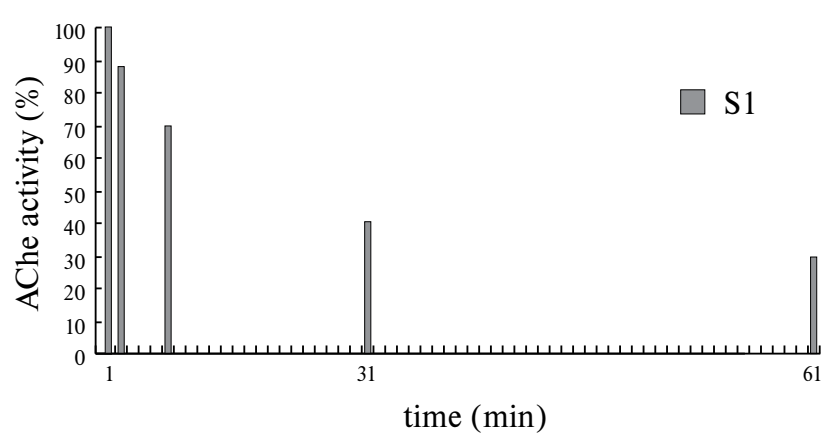

Inhibition of AChE molecular forms

The changes of AChE molecular forms were studied at time of developed intoxication and at time very near to death. These changes are summarized in Table 2.It is clear that the most sensitive was the form 4 having the lowest electrophoretic mobility. Its activity is reaching the zero at the time of death. On the other hand, the forms with highest electrophoretic mobility (forms 1 and 2) were relatively resistant to the inhibitory effect of OPs used (Table 2).

Table 2: Changes of total AChe activity and its molecular forms following sarin, soman and VX poisoning

\begin{tabular}{|c|c|c|c|c|c|}
\hline \multirow{2}{*}{ time } & Total AChe & form $\mathbf{1}$ & form $\mathbf{2}$ & form $\mathbf{3}$ & form 4 \\
\cline { 2 - 5 } & SARIN & $\mathbf{8}$ & $\mathbf{1 0}$ & $\mathbf{3 4}$ & $\mathbf{4 8}$ \\
\hline min & \% control & \% control & \% control & \% control & \% control \\
\hline \hline 5 & $39.0 \pm 1.4$ & $93.3 \pm 6.8$ & $35.5 \pm 4.5$ & $70.0 \pm 4.9$ & $9.2 \pm 2.5$ \\
\hline 10 & $10.0 \pm 1.8$ & $87.7 \pm 4.6$ & $18.7 \pm 5.4$ & $14.0 \pm 3.2$ & $3.0 \pm 1.8$ \\
\hline & SOMAN & & & & \\
\hline 5 & $25.0 \pm 3.5$ & $95.5 \pm 5.4$ & $31.2 \pm 4.0$ & $44.0 \pm 2.6$ & $8.2 \pm 3.9$ \\
\hline 10 & $5.2 \pm 1.1$ & $80.3 \pm 7.6$ & $13.0 \pm 5.1$ & $9.3 \pm 0.6$ & $1.5 \pm 2.1$ \\
\hline & $\mathbf{V X}$ & & & & \\
\hline 30 & $40.2 \pm 4.1$ & $94.3 \pm 5.8$ & $70.0 \pm 4.9$ & $62.2 \pm 4.1$ & $13.2 \pm 4.9$ \\
\hline 60 & $29.7 \pm 2.4$ & $94.3 \pm 5.3$ & $64.8 \pm 5.0$ & $39.8 \pm 3.4$ & $5.3 \pm 2.2$ \\
\hline
\end{tabular}


For this reason, a distribution profile of different forms was drastically changed and the main part of the whole activity was represented by forms 1 and 2 as it is demonstrated in Fig. 4. However, this change was relative only because the calculation of percentage distribution was made using the values decreased.

Fig. 3: Changes of $\mathrm{AChE}$ activities following intoxication with sarin and soman. Semilogarithmic transformation.

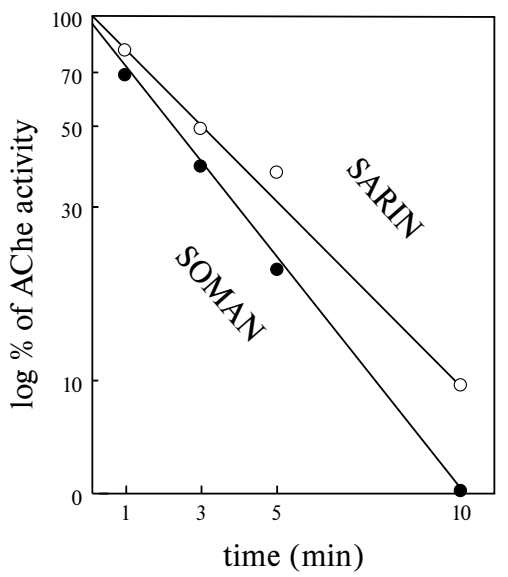

Fig. 4: Changes in relative distribution of the AChE forms following sarin, soman and VX intoxication.

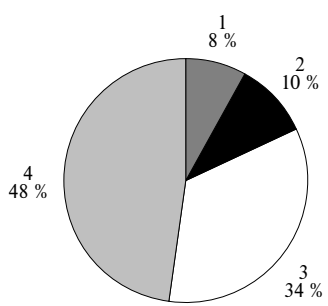

CONTROL

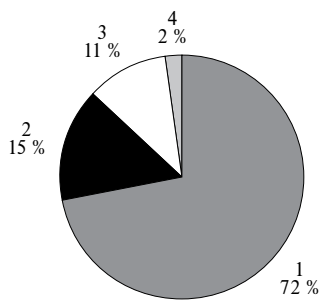

SARIN

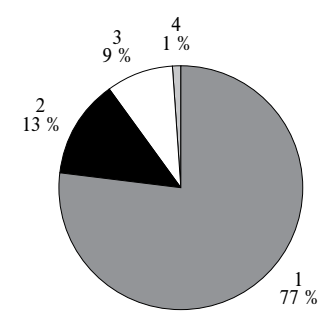

SOMAN

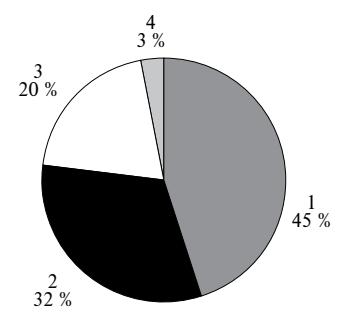

VX

When the values are expressed as the activity for each form as $100 \%$, it is possible to compare real values of $\mathrm{AChE}$ activity determined for the unseparated enzyme and calculated (as weighted means) values of different molecular forms (Table 3 ). It is demonstrated that real and calculated values are in very good agreement differing from 0.1 (minimum) to 6.1 (maximum) \%. It means that really determined
$\mathrm{AChE}$ activity is corresponding to distribution of $\mathrm{AChE}$ molecular forms and therefore, the whole activity is a „mean“ of the activities of AChE molecular forms.

Table 3: AChe activity and its molecular forms following sarin, soman and VX poisoning: real and calculated values

\begin{tabular}{|c|c|c|c|c|c|c|c|c|c|c|}
\hline \multirow{2}{*}{$\begin{array}{l}\text { time } \\
\min \end{array}$} & \multicolumn{2}{|c|}{$\begin{array}{c}\text { Total AChe } \\
\text { SARIN }\end{array}$} & \multicolumn{2}{|c|}{$\begin{array}{c}\text { form } 1 \\
8 \\
\end{array}$} & \multicolumn{2}{|c|}{$\begin{array}{c}\text { form } 2 \\
10\end{array}$} & \multicolumn{2}{|c|}{$\begin{array}{c}\text { form } 3 \\
34 \\
\end{array}$} & \multicolumn{2}{|c|}{$\begin{array}{c}\text { form } 4 \\
48 \\
\end{array}$} \\
\hline & REAL. & CALC. & $\%$ cont. & $\%$ total & $\%$ cont. & $\%$ total & $\%$ cont. & $\%$ total & \% cont. & $\%$ total \\
\hline 5 & 39.0 & 39.1 & & 7.3 & 35.5 & 3.6 & 70.0 & 23.8 & 9.2 & 4.4 \\
\hline \multirow[t]{2}{*}{10} & 10.0 & 15.1 & 87.7 & 7.0 & 18.7 & 1.9 & 14.0 & 4.8 & 3.0 & 1.4 \\
\hline & \multicolumn{2}{|c|}{ SOMAN } & & & & & & & & \\
\hline 5 & 25.0 & 29.6 & 95.5 & 7.6 & 31.2 & 3.1 & 44.0 & 15.0 & 8.2 & 3.9 \\
\hline \multirow[t]{2}{*}{10} & 5.2 & 11.3 & 80.3 & 6.4 & 13.0 & 1.3 & 9.3 & 3.2 & 1.5 & 0.7 \\
\hline & \multicolumn{2}{|c|}{ VX } & & & & & & & & \\
\hline 30 & 40.2 & 41.9 & 94.3 & 7.5 & 70.0 & 7.0 & 62.2 & 21.1 & 13.2 & 6.3 \\
\hline 60 & 29.7 & 30.0 & 94.3 & 7.5 & 64.8 & 6.5 & 39.8 & 13.5 & 5.3 & 2.5 \\
\hline
\end{tabular}

\section{Discusion}

It appears from our results that inhibition of the brain AChE by $\mathrm{G}$ compounds (sarin and soman) is very fast reaching to $50 \%$ activity within minutes. For VX, there is a delay and decrease of AChE activity was observed after more than twenty minutes. The half-lives are very dependent on the dose of the agent administered, on the species and other factors and therefore it is difficult to compare our results. In general, inhibition of $\mathrm{AChE}$ in vivo is faster for G-compounds in comparison with V-compounds $(1,8,25)$.

From our results describing multiple molecular forms of $\mathrm{AChE}$ can be concluded that $\mathrm{AChE}$ in the brain exists in molecular forms. These forms were observed also by other authors $(3,5,12,13,31,40,43)$. These forms are different for various species. However, the electrophoretic mobility of AChE components from the rat, rabbit, mouse and human brains suggested that there are generally two types of AChE forms having high and low molecular weight. One $\mathrm{BuChE}$ and two AChE bands in the rat hippocampus after electrophoresis in polyacrylamide gel were observed (41). The distinction between the two AChE forms is difficult without electrophoresis. They differ in electrophoretic mobility and they can be well differentiated by electrophoresis.

Subcellular localization of AChE suggested that in nerve ending particles and microsomal fractions 2 - $4 \mathrm{AChE}$ forms are present, in the mitochondrial fraction only one was detected (4). The microsomal form absent in the mitochondrial fraction is the most sensitive to OPs in vivo. From previous studies is known that high molecular form of AChE has the lowest $\mathrm{K}_{\mathrm{m}}$ value (2) and the highest decrease of this component after deafferentation was also observed (3). These results suggested that this form of AChE would be very important for normal cholinergic nerve transmission. It arises the question on existence of the forms under physiological conditions. Using thermal dena- 
turation, it was demonstrated that they are not artifacts formed during homogenization or other treatment of the brain tissue (5). These findings were also described by other authors $(2,5,23,25,33,41,43)$. The overall data show that catalytic activity of AChE molecular forms is different and their inhibition by various inhibitors may be heterogeneous. This heterogeneity was demonstrated for AChE phosphorylating inhibitors as well as for inhibitors with different binding sites for the enzyme.

The results with another type of inhibitor - 7-methoxytacrine (7-MEOTA) fit well with our previous findings indicating a greater sensitivity of slowly migrating molecular forms separated by polyacrylamide gel electrophoresis (10). In fact, it has been demonstrated recently that slowly migrating forms of cortical AChE correspond to $\mathrm{G}_{4}$ forms separated by sedimentation analysis (43). On the other hand, recent data indicate an almost equal sensitivity of $G_{4}$ and $G_{1}$ forms of both soluble and membrane-bound whole brain AChE to this type of inhibitor (31). It is not excluded that the reversible inhibitors such as 7-MEOTA modify its interaction with the active site resulting in a preferential inhibition of $\mathrm{G}_{4}$ forms. It is of interest that the introduction of a heptyl group into physostigmine modified its interaction with the AChE molecular forms, heptylphysostigmine showed a stronger inhibition for $G_{1}$ than for $G_{4}$ forms while in the case of the parent compound similar inhibition of the 2 forms was observed (31).

The data of 7-MEOTA are different from those obtained for DFP and paraoxon showing similar IC $_{50}$ values for $\mathrm{G}_{4}$ and $\mathrm{G}_{1}$ forms (43). These findings have been confirmed for membrane-bound $\mathrm{AChE}$ (31). This is not surprising since the interaction of OP compounds (and physostigmine) with the active site of enzymatic molecule is different from that for 7-MEOTA-type compounds. In fact, OP compounds inhibit AChE by phosphorylating the esteratic serine in the catalytic site. On the other hand, acridine derivatives bind to the hydrophobic area close to the active site of AChE simultaneously affecting its catalytic center via an allosteric mechanism $(20,32,38)$.

As regards the data on AChE molecular forms, they confirm previous findings indicating a more pronounced sensitivity of $\mathrm{G}_{4}$ forms, as compared to $\mathrm{G}_{1}$ forms, in brain of rats injected with paraoxon (43). Somewhat lower inhibitory effects of the same dose of paraoxon $(0.25 \mathrm{mg} / \mathrm{kg}$ s.c.) as well as a somewhat lower contribution of $\mathrm{G}_{4}$ forms to total AChE activity in untreated rats were observed in another experiments (11) in comparison with those reported by Volpe et al. (43) and may depend on regional differences (cerebral cortex and whole brain).

In the case of brain $\mathrm{AChE}$, as has been pointed out (43), $G_{4}$ and $G_{1}$ forms represent distinct pools in the cell, the former being mainly associated with membranes, with its catalytic site exposed to the extracellular space, and the latter confined to the intracellular compartment.

It appears from our results that following intoxication with nerve agents studied the highest sensitivity for high molecular AChE form was observed. Determination of the whole AChE activity is partly misrepresenting because of different distribution of AChE molecular forms in the sample. Following determination of the whole activity, a „mean“ activity containing activities of the forms is determined. It can be concluded that in studies requiring high sensitivity (e.g. the studies of antidotal action), AChE molecular forms could be of choice for more detailed information on functional stage of AChE - important marker of cholinergic nerve transmission.

\section{Acknowledgement}

The author wishes to thank Mrs M. Zechovská and Mrs E. Vodáková for skilled technical assistance and Mrs E. Komárková for preparation of the manuscript. The work was partly supported by the Ministry of Defence and GA ČR No 307/95/1537.

\section{References}

1. Andersen RA, Aaraas I, Gaare G, Fonnum F. Inhibition of acetylcholinesterase from different species by organophosphorus compounds, carbamates and methylsulphonylfluoride. Gen Pharmacol 1977;8:331-4.

2. Bajgar J, Žižkovský V. Partial characterization of soluble acetylcholinesterase isoenzymes of the rat brain. J Neurochem 1971;18:1609-14.

3. Bajgar J, Pařizek J. Changes of acetylcholinesterase and esterase isoenzymes in isolated cerebellar cortex of the rabbit. Brain Res 1973;57:299-305.

4. Bajgar J. Characterization and properties of multiple molecular forms of acetylcholinesterase. Possible evaluation in histochemistry. Acta Histochem 1975;15(Suppl.):123-32.

5. Bajgar J. Isoenzymes of rat brain acetylcholinesterase: facts or artifacts? J Neurochem 1979;32:1875-9.

6. Bajgar J. Intoxikace organofosforovými inhibitory cholinesteráz - účinek, diagnóza a terapie. 1st ed. Avicenum: Praha 1985:7-40.

7. Bajgar J. The influence of inhibitors and other factors on cholinesterases. Sb Ved Pr Lek Fak Karlovy University Hradec Králové 1991;34:3-75.

8. Bajgar J. Biological monitoring of exposure to nerve agents. Brit J Ind Med 1992;49:648-53.

9. Bajgar J, Kassa J, Krs O, Fusek J. Inhibition of rabbit erythrocyte acetylcholinesterase by soman. 5th International Symposium on Protection against CBWA. Stockholm, Sweden, 11-16 June 1995.

10. Bajgar J, Michalek H, Bisso GM. Differential inhibition of rat brain acetylcholinesterase molecular forms by 7-methoxytacrine in vitro. Toxicol Lett 1995;80:109-14.

11. Bajgar J, Michalek H, Bisso GM. Differential reactivation by HI-6 in vivo of Paraoxon-inhibited rat brain acetylcholinesterase molecular forms. Neurochem Int 1995; 26:347-50.

12. Brimijoin S, Rakonczay Z. Immunocytology and molecular histology of cholinesterases: current results and prospects. Int Rev Neurobiol 1986;28:353-410. 
13. Brownson RH, Mc Dougal HD, Suter BD, Vijayan VK. Parathion-induced alterations in chemical, biochemical and isoenzyme study. In: Neurotoxicology (L. Roizin, H. Shirachi and N. Grcevic, Eds.), New York, Raven Press, 1977:457-68. 14. Buccafusco JJ, Graham JH, VanLingen J, Aronstam RS. Protection afforded by clonidine from the acute and chronic behavioral toxicity produced by the cholinesterase inhibitor soman. Neurotoxicol Teratol 1989;11:39-44.

15. Clement JG. Survivors of soman poisoning: recovery of the soman LD50 to control value in the presence of extensive acetylcholinesterase inhibition. Arch Toxicol 1989;63: 150-4.

16. Clement JG, Hand BT, Shilhoff JD. Differences in the toxicity of soman in various strains of mice. Fund Appl Toxicol 1981;1:419-20.

17. Dawson RM. Review of oximes available for treatment of nerve agent poisoning. J Appl Toxicol 1994;14:317-31.

18. Ellman GL, Courtney DK, Andres V, Featherstone RM. A new and rapid colorimetric determination of acetylcholinesterase activity. Biochem Pharmacol 1961; 7:88-95.

19. FOA report: Fifth International Symposium on Protection against Chemical Warfare Agents. Proceedings, B 95-00122-4.9-SE, Stockholm-Umea, 1995:1-436.

20. Freeman SE, Dawson RM. Tacrine: a pharmacological review. Prog Neurobiol 1991;36:257-77.

21. Jokanovic M. Liver esterases and soman toxicity in the rat following partial hepatectomy. Biochem Pharmacol 1990;39:797-9.

22. Kadar T, Raveh L, Cohen G et al. Distribution of $3 \mathrm{H}-$ soman in mice. Arch Toxicol 1985;58:45-9.

23. Kaliste-Korhonen E, Ryhanen R, Ylitalo P, Hanninen O. Cold exposure decreases the effectiveness of atropineoxime treatment in organophosphate intoxication in rats and mice. Gen Pharmacol 1989;20:805-9.

24. Kovačevič V, Maksimovič M. Protective effects of mixture of oximes in poisoning by nerve chemical warfare agents. Acta Pharm Yugoslav 1991;41:75-8.

25. Lenz DE, Maxwell DM. Inhibition of rat cerebrum acetylcholinesterase isoenzymes after acute administration of soman. Biochem Pharmacol 1981;30:1369-71. 26. Little PJ, Scimeca JA, Martin BR. Distribution of /H3/diisopropylfluorophosphate, /H3/soman, /H3/sarin, and their metabolites in mouse brain. Drug Metab Disp 1988;16: 515-20.

27. Maekawa K. The sarin poisoning incident in Tokyo subway. Přednáška na The Fifth International Symposium on Protection Against CBWA, Stockholm, June 11-16, 1995.

28. Marrs TC, Maynard RL, Sidell FR. Chemical warfare agents. Toxicology and treatment. J. Wiley and Sons. Chicester, New York, Brisbane,Toronto,Singapore, 1996:1243.

29. Maxwell DM, Brecht KM. The role of carboxylesterase in species variation of oxime protection against soman. Neurosci Biobehav Rev 1991;15:135-9.

30. Michalek H, Meneguz A, Bisso GM. Molecular forms of rat brain acetylcholinesterase in DFP intoxication and subsequent recovery. Neurobehav Toxicol Terratol 1981:3:303-12.

31. Ogane N, Giacobini E, Messamore E. Preferential inhibition of acetylcholinesterase molecular forms in rat brain. J Neurochem 1992;17:489-95.

32. Patočka J, Bajgar J, Bielavský J, Fusek J. Kinetics of inhibition of cholinesterase by 1,2,3, 4-tetrahydro-9-aminoacridine. Collect Czech Chem Commun 1976;41:816-24.

33. Rakonczay Z. Cholinesterase and its molecular forms in pathological states. Progr Neurobiol 1988;31:311-30.

34. Shapira S, Kadar T, Cohen G, Chapman S, Raveh L. Effets of CBDP and MEPQ on the toxicity and distribution of /H3/-somanin mice. Arch Toxicol 1990;64:663-8.

35. Shih TM, Penetar DM, McDonough JH, Romano JA, King JM. Age-related differences in soman toxicity and in blood and regional cholinesterase activity. Brain Res Bull 1990;24:429-36.

36. Skau KA. Mammalian acetylcholinesterase:molecular forms. Comp Biochem Physiol 1986;83C:225-7.

37. Skopec F, Bajgar J. Anticholinesterase action of organophosphates: importance of the liver. Sb Ved Pr Lek Fak Karlovy Univerzity Hradec Králové 1993;36:83-92.

38. Soreq H, Gnatt A, Loewenstein Y, Neville LF. Excavations into the active site-gorge of cholinesterase. TIBS 1992;17:353-8.

39. Taylor P. Anticholinesterase agents. In: Gilman AG, Goodman LS, Rall TW and Murad F (Eds.), Goodman and Gilman's The Pharmacological Basis of Therapeutics, 7th ed. MacMillan, New York, 1985:1-129.

40. Traina ME, Serpietri LA. Changes in the levels and form of rat plasma cholinesterases during chronic diisopropylphosphorofluoridate intoxication. Biochem Pharmacol 1984;33:645-53.

41. Uhlig M, Luppa H. Charakterisierung esterspaltender Enzyme des Gehirns mit Hilfe der Polyacrylamid-GelElektrophorese. Acta histochem 1975; 15(Suppl.):133-7.

42. Vachek J, Geršl V, Fusek J, Krs O, Skopec F, Bajgar J. Toxicities of O-alkyl S-(2-dialkylaminoethyl) methyl phosphonothiolates (V-compounds). Acta Medica (Hradec Králové) 1996;39:67-71.

43. Volpe MT, Bisso GM, Michalek H. In vivo and in vitro effects of diisopropyl fluorophosphate and paraoxon on individual molecular forms of rats brain acetylcholinesterase. Neurochem Res 1990;15:975-80.

44. Yanagisawa N. A medical survey of patients from the „organophosphorus poison gas (sarin) poisoning“ of 27 June 1994 examined at hospitals in Matsumoto City. Japan Non-paper for discussion, Second Meeting of the Task Force on Medical Treatment (Haag, 2.-5.5.1995).

Submitted October 1997.

Accepted November 1997.

Doc. MUDr. Jiří Bajgar, DrSc., Military Medical Academy, 50001 Hradec Králové, Czech Republic. 